\title{
Effects of hot isostatic pressing temperature on casting shrinkage densification and microstructure of Ti6Al4 $\mathrm{V}$ alloy
}

\author{
Qian Xu', * Jian-xin Zhou', Hai Nan², Ya-jun Yin', Min Wang', ${ }^{1}$, Xu Shen ${ }^{1}$ and Xiao-yuan Ji ${ }^{1}$ \\ 1. State Key Laboratory of Materials Processing and Die \& Mould Technology, Huazhong University of Science and Technology, Wuhan 430074, \\ China \\ 2. Beijing Institute of Aeronautical Materials, Aviation Industry of China, Beijing 100095, China
}

\begin{abstract}
The Ti6Al4V alloy castings were produced by the investment casting process, and the hot isostatic pressing (HIP) was used to remove shrinkage from castings. The processing pressure and holding time for HIP were $150 \mathrm{MPa}$ and $20 \mathrm{~min}$, respectively. Four different HIP temperatures were tested, including $750{ }^{\circ} \mathrm{C}, 850{ }^{\circ} \mathrm{C}$, $920{ }^{\circ} \mathrm{C}$ and $950{ }^{\circ} \mathrm{C}$. To evaluate the effects of temperature on densification and microstructure of Ti6Al4V alloy treated by HIP, non-destructive testing and metallographic observation was performed. The experimental results show that the shrinkage was completely closed at $920^{\circ} \mathrm{C}$ and $950{ }^{\circ} \mathrm{C}$. The densification of Ti6Al4V alloy increased as the HIP temperature increased below $920^{\circ} \mathrm{C}$. The lamellae were more uniform, the thickness of lamellae was obviously broadened and the structure was coarsen. Besides, the Norton creep equation was used to simulate the effect of different temperatures on the densification of Ti6Al4V alloy during HIP. The simulation results were in good agreement with the experimental results. It was also found that $920^{\circ} \mathrm{C}$ is a suitable temperature for HIP for Ti6Al4V alloy.
\end{abstract}

Key words: Ti6Al4V alloy; hot isostatic pressing; temperature; casting shrinkage; densification; microstructure
CLC numbers: TP391.99
Document code: A
Article ID: 1672-6421(2017)05-429-06

$\mathrm{T}$ i6Al4V alloy has the properties of small density, high strength and good corrosion resistance. However, Ti6Al4V alloy castings are prone to shrinkage porosity due to its poor fluidity, leading to the poor performance of components. The defects must be reduced to a minimum level, especially in the field of aerospace and other high-quality-requirement industry. Hot isostatic pressing (HIP) has been proved to be a very effective way to eliminate or reduce shrinkage. A workpiece is heated and put under uniform pressure by inert gas, and the shrinkage is eliminated without changing the shape by the mechanism of plastic deformation, creep and diffusion bonding ${ }^{[1-2]}$.

For decades, remarkable work has been done on the effect of HIP temperature on alloy's densification and microstructure. Gang Wang ${ }^{[2]}$ et al. have studied the influence of HIP temperature on the microstructure of $2 \mathrm{~A} 12$ powder compact. It was found that the microstructure

\section{*Jian-xin Zhou}

Male, born in 1975, Professor, Ph.D. His research interests mainly focus on the computer applications in foundry industry, especially on casting process simulation and intelligent manufacturing for foundry enterprises.

E-mail: zhoujianxin@mail.hust.edu.cn

Received: 2017-08-15; Accepted: 2017-09-05 of raw powders changed from a dendrite structure to an equiaxed structure from room temperature to $600{ }^{\circ} \mathrm{C}$. Lei $\mathrm{Xu}^{[3]}$ also investigated the effects of temperature and pressure on microstructure of powder compacts during HIP. Through the comparison of the samples HIPped at $800{ }^{\circ} \mathrm{C}$ and $910{ }^{\circ} \mathrm{C}$, it was found that more stable and homogeneous microstructure can be obtained at higher temperature. Chung-Hung Tam ${ }^{[4]}$ et al. have studied the effects of three different HIP temperatures 1,323 K, 1,373 $\mathrm{K}$ and $1,423 \mathrm{~K}$ on the densification of $\mathrm{Cr}$-Si targets, and it was found $1,373 \mathrm{~K}$ was a suitable HIP temperature for the three Cr-Si targets. Yu Zhou ${ }^{[5]}$ investigated the effects of HIP temperature on the densification of Nibased superalloy. It was found that HIP temperature played a dominant role in the cavity healing process. With gradually increasing HIP temperature, the cavity healing behaviors were revealed.

The previous research mainly focused on studying the effects of HIP temperature by experiments. The change process of the shrinkage inside the castings is difficult to be observed by experiment, but it can be easily observed through the simulation of HIP. In addition, it is more convenient to use simulation to explore the effects of HIP temperature on densification of Ti6Al4V alloy due to its high casting environment requirements. 
In this study, experiment and simulation were both used to investigate the influence of HIP temperature on densification and microstructure of Ti6Al4V alloy. Experiments including HIP, non-destructive testing and metallographic observation were carried out to study the effect of HIP temperature on densification and microstructure of Ti6Al4V alloy. The simulation was used to explore the effect of HIP temperature on densification of Ti6Al4V alloy and find an appropriate HIP temperature for Ti6A14V alloy.

\section{Experiment}

\subsection{Experimental procedure}

Ti6Al4V alloy rods, as shown in Fig. 1, were produced using investment casting with Ti6Al4V alloy. It's not sure whether there were large shrinkages in all rods, so more rods were fabricated than the actual required.

Before HIP, non-destructive testing was performed. The X-ray fluoroscopy method was used to detect the internal shrinkage of the castings. In order to determine the exact location of the shrinkage, after the first X-ray shooting, the specimen needed to
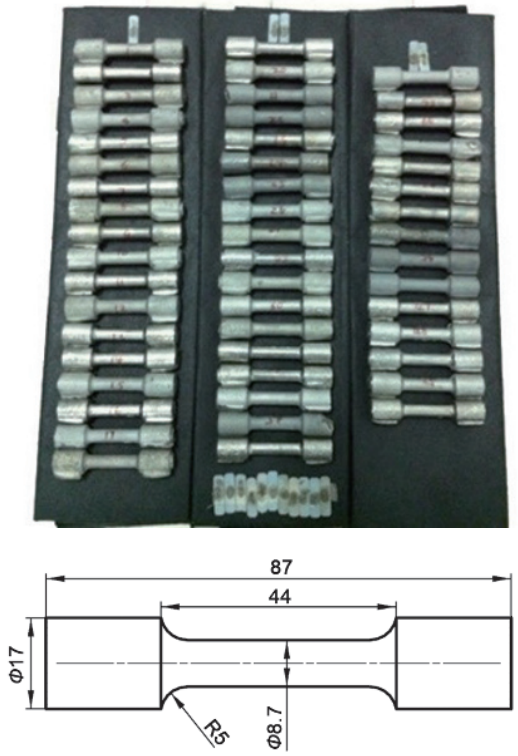

Fig. 1: Ti6Al4V alloy casting rods used in experiment be turned $90^{\circ}$ to carry on the second shooting. Then the X-ray film viewer was used to observe the photos. To facilitate the measurement of hole size and dissection of the rods after HIP, rods with shrinkage of regular shape and close to the center axis of the castings were chosen to be treated by HIP. The type of HIP equipment is QIH-9. It's maximum operating temperature and pressure are $2000{ }^{\circ} \mathrm{C}$ and $200 \mathrm{MPa}$, respectively. The working size of HIP equipment is $\Phi 150 \times 300 \mathrm{~mm}^{2}$.

The rods were grouped according to HIP temperatures, as shown in Table 1. The rod numbered \#12 was not treated by HIP as a reference. The processing pressure and holding time for HIP treatment were $150 \mathrm{MPa}$ and $20 \mathrm{~min}$, respectively. Four different HIP temperatures were utilized, $750{ }^{\circ} \mathrm{C}, 850{ }^{\circ} \mathrm{C}, 920^{\circ} \mathrm{C}$ and $950^{\circ} \mathrm{C}$. After HIP, the rods were cooled in the furnace to $200^{\circ} \mathrm{C}$.

\section{Table 1: Sample grouping}

$\begin{array}{cc}\text { Rod number } & \text { HIP temperature }\left({ }^{\circ} \mathrm{C}\right) \\ \# 3, \# 5, \# 6, & 750 \\ \# 7, \# 9, \# 10 & 850 \\ \# 11, \# 13, \# 15 & 920 \\ \# 16, \# 19, \# 2 & 950 \\ \# 12 & \text { Without HIP }\end{array}$

After the HIP treatment, X-ray fluoroscopy method was performed again to inspect the internal flaw. Then \#3, \#7, \#11, $\# 16$ and \#12 rods were sectioned. Cross sections were grinded and polished by mechanical method. The as-cast sample together with the as-HIPed samples were etched in Kroll etchants with a composition of $1 \mathrm{ml} \mathrm{HF}, 3 \mathrm{ml} \mathrm{HNO}_{3}$ and $96 \mathrm{ml}$ $\mathrm{H}_{2} \mathrm{O}$. Finally, a metallographic microscope was used to observe the densification and microstructure of samples.

\subsection{Results and discussion}

The results of X-ray fluoroscopy are shown in Fig. 2. It can be seen that large and concentrating shrinkage cavities were located at the two ends with a larger radius of the samples. The X-ray films of all the Ti6Al4V alloy casting samples in two directions perpendicular to each other before HIP are shown in Fig. 2(a) and Fig. 2(b), and the ones after HIP are shown in Fig.

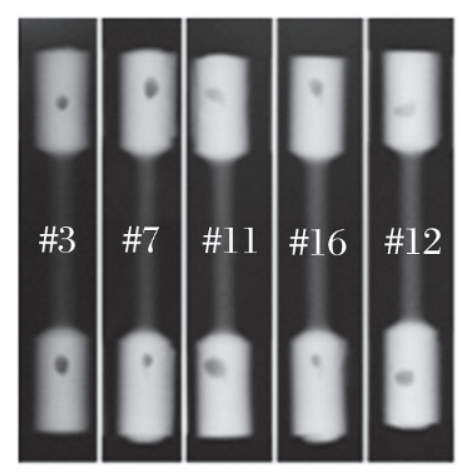

(a) First X-ray shooting before HIP

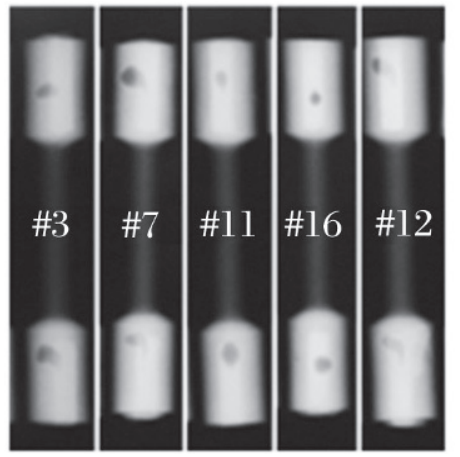

(b) Second X-ray shooting before HIP

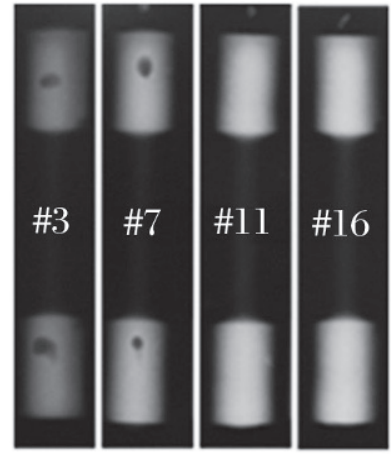

(c) First X-ray shooting after HIP

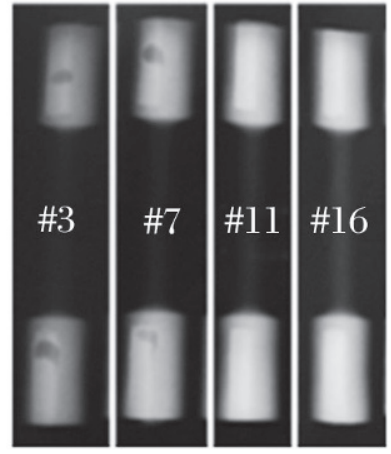

(d) Second X-ray shooting after HIP

Fig. 2: X-ray film of internal shrinkage 
2(c) and Fig. 2(d). It can be seen that shrinkage didn't change significantly after $750{ }^{\circ} \mathrm{C}$ and $850{ }^{\circ} \mathrm{C}$ HIP, while the shrinkage was completely eliminated after HIP at $920^{\circ} \mathrm{C}$ and $950{ }^{\circ} \mathrm{C}$.

The mechanical properties of Ti6Al4V alloy have a significant change as temperature increases. The elastic modulus and yield strength of Ti6Al4V alloy decrease obviously as temperature increases ${ }^{[10]}$. The material will undergo obvious plastic flow at high temperature ${ }^{[11]}$. It is known that the liquidus temperature $\left(T_{\mathrm{m}}\right)$ of Ti6Al4V alloy is $1,663{ }^{\circ} \mathrm{C}{ }^{[9]}$. When the temperature reaches $0.3 T_{\mathrm{m}}$, a significant creep phenomenon will occur. When the absolute temperature $\geqslant 0.5 T_{\mathrm{m}}$, Ti6Al4V alloy will undergo obvious creep deformation. As temperature rises, the diffusion coefficient increases sharply, as well as the vacancy concentration, which is beneficial to the diffusion of atoms. Therefore, when HIP temperature is reasonable, the shrinkage will be eliminated eventually under the combined actions of plastic flow, creep and diffusion bonding.

The metallographic figures of sections around shrinkage before and after HIP were observed. There were coarse grains at the edge and the grain size is not uniform in the as-cast sample as shown in Fig. 3(a). After HIP, the grain size became uniform. However, grains grew as HIP temperature increased. Shrinkage was completely closed at $920^{\circ} \mathrm{C}$ and $950{ }^{\circ} \mathrm{C}$, and the microstructure at the location of original shrinkage turned into chrysanthemum-like, which indicated plastic flow occurred in the process of shrinkage elimination.

Figure 4 shows the microstructures of Ti6Al4V alloy before and after HIP. It can be seen that the microstructure of as-cast and as-HIPed Ti6Al4V alloy were all composed of cluster-like sheet $\alpha$, inter-lamellar $\beta$ and grain boundary $\alpha$. Before HIP, the thickness of lamellae of as-cast Ti6Al4V alloy was not uniform and the direction was chaotic, as shown in Fig. 4(a). After HIP, the microstructures were uniformly distributed and the thickness of lamellae was obviously broadened. The structure was coarse due to the high holding temperature. These are the reasons for the decrease of the strength and the improvement of plasticity of the Ti6Al4V alloy after HIP.

The HIP treatment plays an important role in the elimination of the shrinkage of Ti6Al4V alloy. At the same time, the side effects of coarsening microstructure was brought about by HIP, which cannot be ignored. Therefore, both the densification of Ti6Al4V alloy castings and the change of microstructure should be taken into consideration when choosing the HIP parameters.

\section{FEM simulation}

\subsection{Constitutive model}

To find an appropriate HIP temperature for Ti6Al4V alloy castings, the commercial FEM software ANSYS was used to simulate the process of HIP. HIP of Ti6Al4V alloy with shrinkage is a process of plastic deformation, creep and diffusion bonding. The total strain is composed of the thermal strain, elastic and plastic strain and creep strain ${ }^{[12]}$. HIP of Ti6Al4V alloy involves a complex thermal and mechanical coupling process ${ }^{[13]}$. The bilinear elastoplastic model and Norton creep model ${ }^{[14]}$ were used in the simulation.
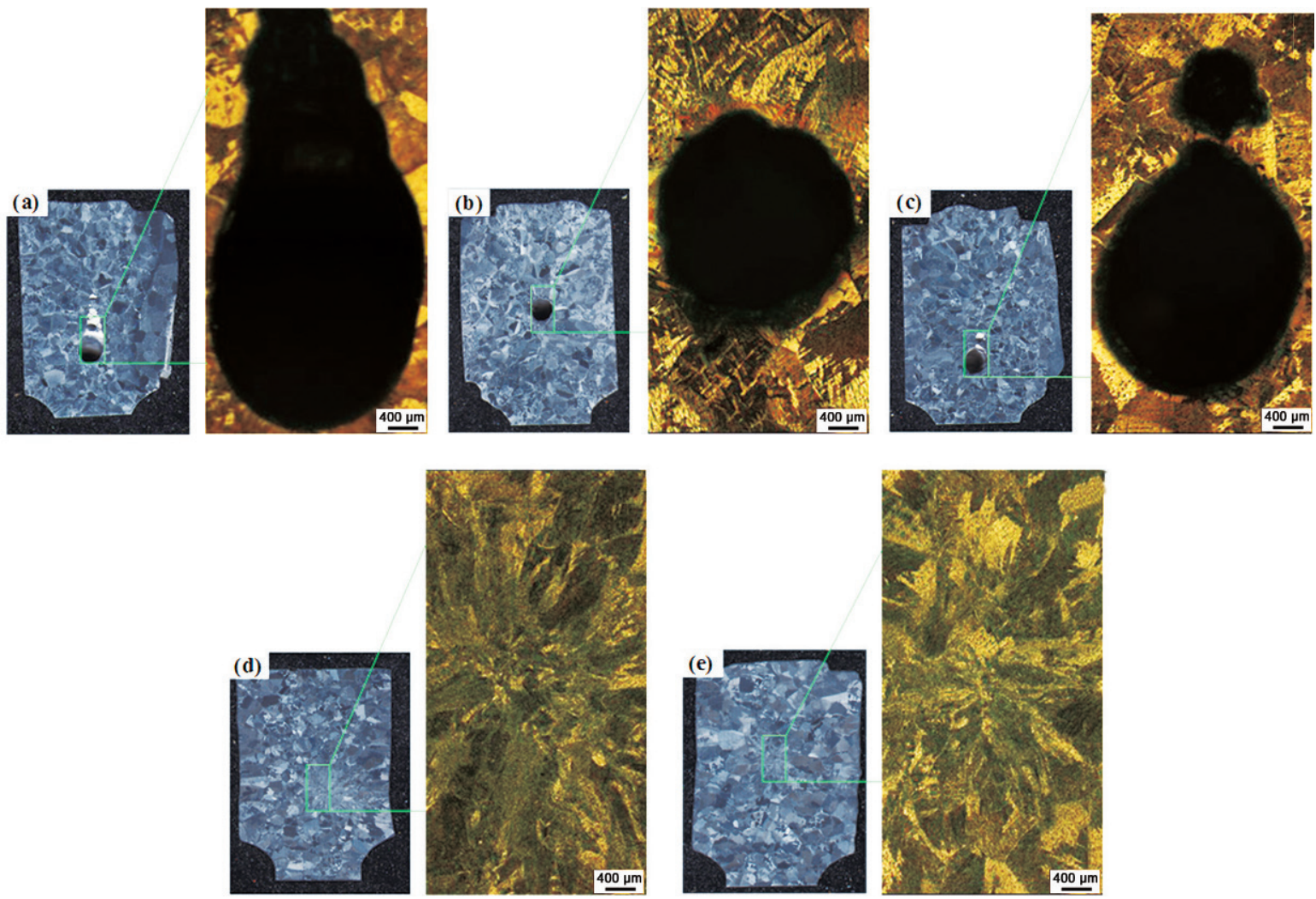

Fig. 3: Metallography of sections around shrinkage: (a) as-cast; (b) HIPed at $750{ }^{\circ} \mathrm{C}$;

(c) HIPed at $850^{\circ} \mathrm{C}$; (d) HIPed at $920^{\circ} \mathrm{C}$; (e) HIPed at $950^{\circ} \mathrm{C}$ 

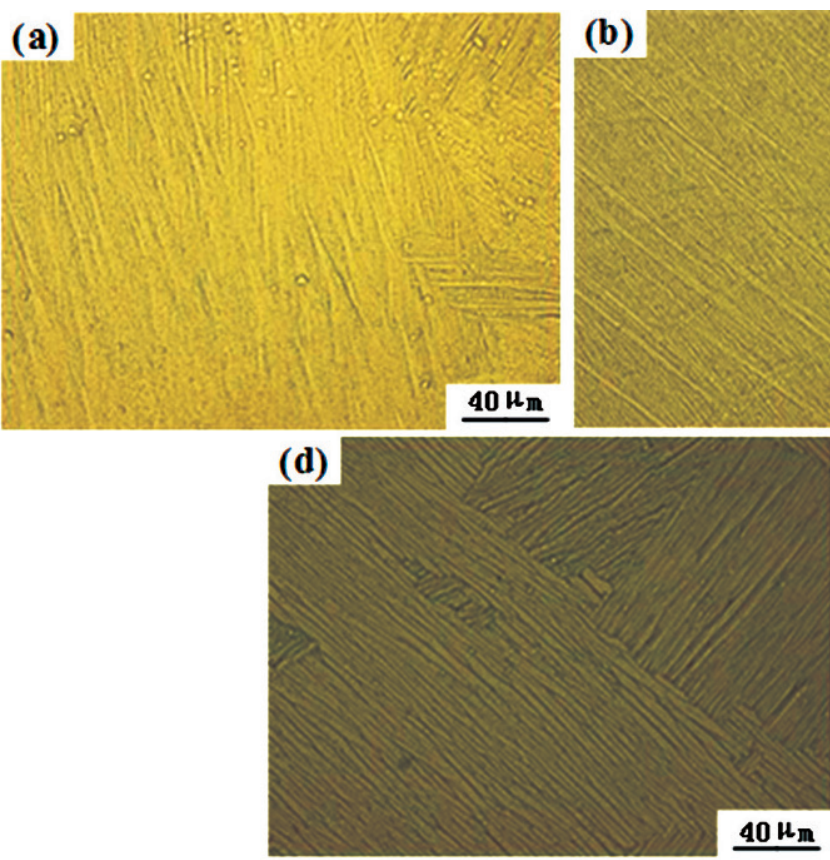
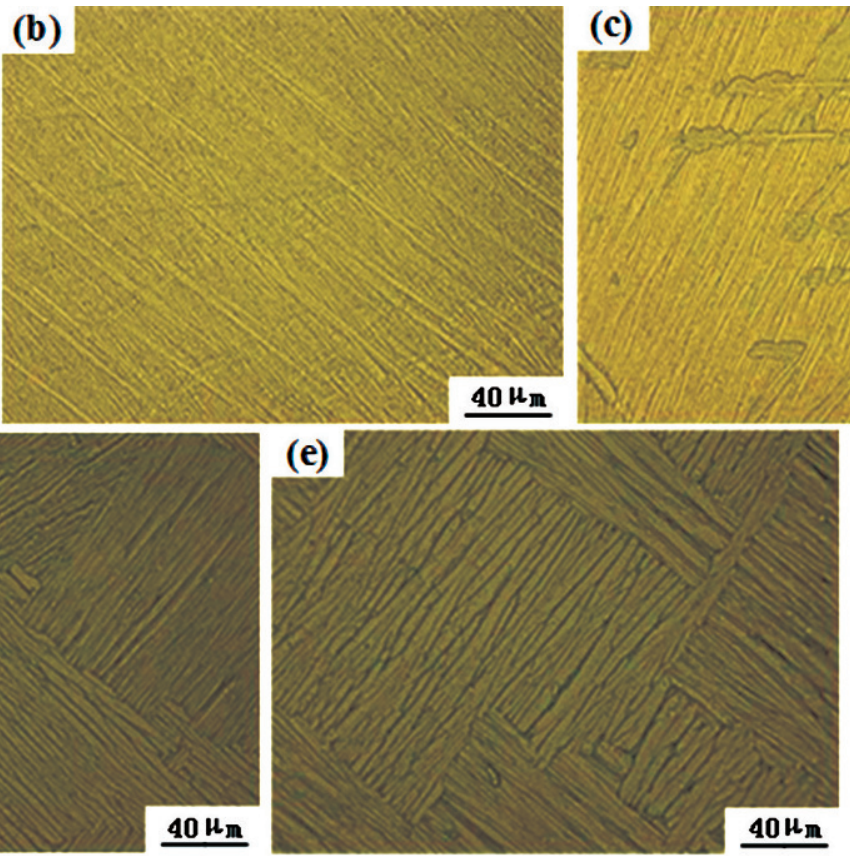

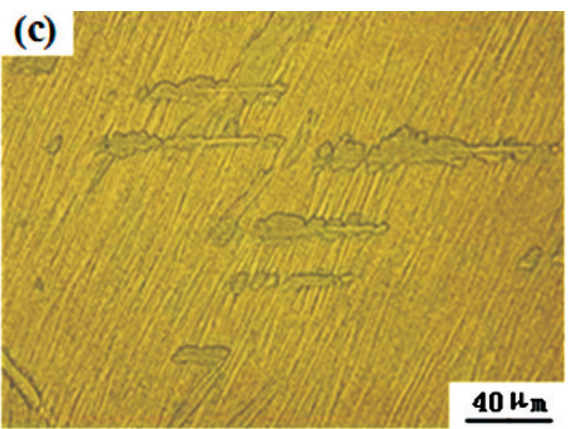

$40 \mu_{m}$

Fig. 4: Metallographic microstructures of Ti6AI4V alloy: (a) as-cast; (b) HIPed at $750{ }^{\circ} \mathrm{C}$; (c) HIPed at $850^{\circ} \mathrm{C}$; (d) HIPed at $920^{\circ} \mathrm{C}$; (e) HIPed at $950^{\circ} \mathrm{C}$

The bilinear elastoplastic model is described as Eq. (1). It assumes that the stress-strain relationship is linear in elastic and plastic phases and the yield point is the inflection point.

$$
\sigma= \begin{cases}E \times \varepsilon & |\varepsilon| \leqslant \varepsilon_{s} \\ {\left[\sigma_{s}+E_{1} \times\left(|\varepsilon|-\varepsilon_{s}\right)\right] \times \operatorname{sgn} \varepsilon} & |\varepsilon|>\varepsilon_{s}\end{cases}
$$

where $\sigma$ is the stress tensor, $\varepsilon$ is the strain tensor, $\varepsilon_{s}$ is the yield strain, $\sigma_{s}$ is the yield stress, $E$ is the young's modulus and $E_{1}$ is the tangent modulus.

The creep curve is divided into three stages ${ }^{[11]}$. In the first stage, the strain increases but the strain rate decreases with time, the duration of this stage is short. The second stage has a constant strain rate, and this stage lasts longer. In the third stage, the strain rate increases rapidly until the damage of the sample. ANSYS only provides the first two stages of the creep model. Taking the calculation of efficiency and accuracy into consideration, the second stage of creep is selected to simulate HIP procedure. The Norton creep model which explains the second stage of creep is described as Eq. $(2)^{[14]}$ :

$$
\dot{\varepsilon}_{c r}=A \sigma^{n} \exp \left(-\frac{Q_{c}}{R T}\right)
$$

where $\dot{\varepsilon}_{c r}$ is the strain rate at steady creep stage, $T$ is the absolute temperature, $n$ is the stress exponent, $Q_{c}$ is the activation energy of creep, $R$ is the gas constant, $\mathrm{A}$ is the material constant.

\subsection{Material properties}

Table 2 lists the mechanical and thermal properties of Ti6Al4V alloy at different temperatures. Because the coefficient of linear expansion has a slight variation with temperature, it is regarded as a constant, $9.9 \mathrm{E}-6^{\circ} \mathrm{C}{ }^{[10]}$. Other parameters used in the simulation come from the material library of ANSYS.

\subsection{Geometry and boundary conditions}

To simplify geometry, a round hole was used to replace the irregularity shrinkage and a half model was analyzed due to its symmetrical structure. Figure 5(a) shows the geometry and Fig. 5(b) shows the mesh of the model. The macro deformation of the shrinkage was mainly studied, so the mesh around the shrinkage portion is denser. Figure 6 shows the boundary

\begin{tabular}{|c|c|c|c|c|c|}
\hline \multirow{2}{*}{ Thermo-mechanical property } & \multicolumn{5}{|c|}{ Temperature $\left({ }^{\circ} \mathrm{C}\right)$} \\
\hline & 25 & 300 & 700 & 900 & 1000 \\
\hline Thermal conductivity $\left(\mathrm{W} \cdot \mathrm{m}^{-1} \cdot \mathrm{K}^{-1}\right)$ & 6.368 & 11.70 & 17.85 & 21.80 & 24.23 \\
\hline Specific heat $\left(\mathrm{J} \cdot \mathrm{Kg}^{-1} \cdot \mathrm{K}^{-1}\right)$ & 589.35 & 636.76 & 786.95 & 1100.7 & 669.66 \\
\hline Young's modulus (GPa) & 114 & 99.6 & 77.2 & 70.2 & 69.6 \\
\hline Poisson's ratio & 0.3201 & 0.3313 & 0.349150 & 0.3663 & 0.3798 \\
\hline Density $\left(\mathrm{kg} \cdot \mathrm{m}^{-3}\right)$ & 4,418 & $4,382.8$ & $4,323.5$ & $4,303.2$ & $4,305.5$ \\
\hline Yield strength (MPa) & 900.13 & 645.06 & 75.92 & 12.4 & 5.22 \\
\hline
\end{tabular}

Table 2: Thermo-mechanical properties of Ti6Al4V alloy at different temperatures 

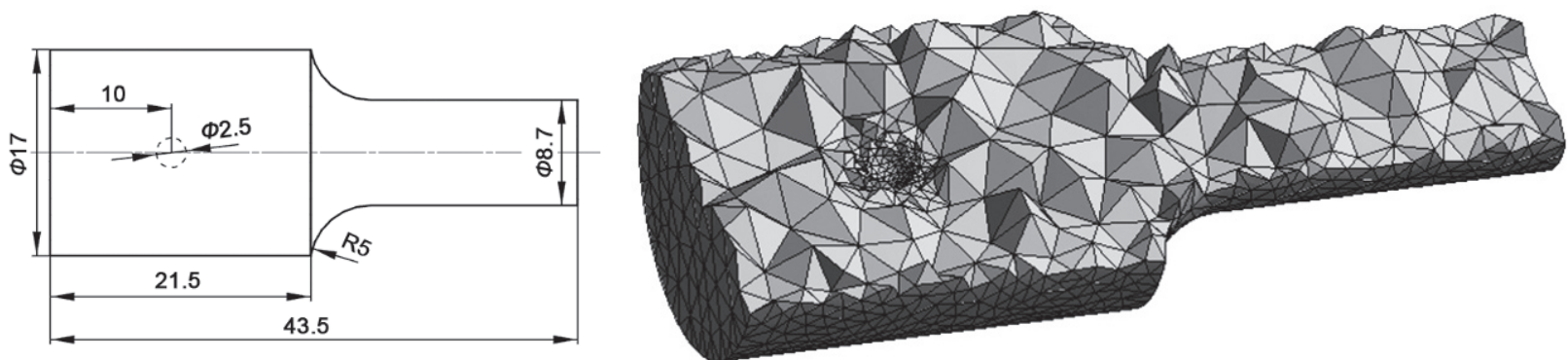

Fig. 5: Geometry used in numerical simulation

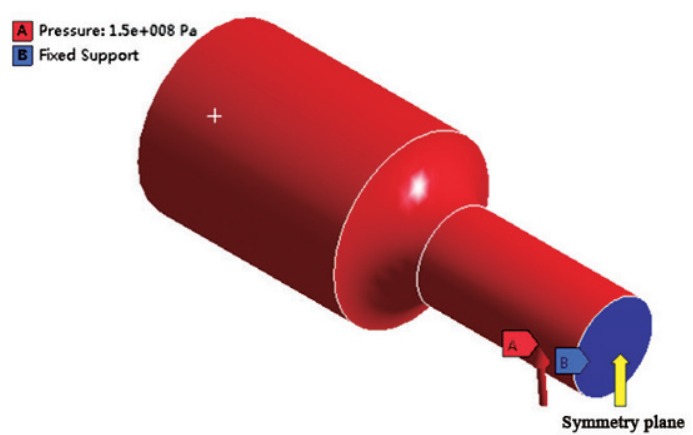

Fig. 6: Boundary conditions of force and displacement conditions of force and displacement. Temperature was also applied on the surface of the model.

\subsection{Simulation results and discussion}

Because the large temperature difference between $850{ }^{\circ} \mathrm{C}$ and $920{ }^{\circ} \mathrm{C}$, HIP at $900{ }^{\circ} \mathrm{C}$ was also simulated. Figure 7 shows the total deformation of the Ti6Al4V alloy at different HIP temperatures.It can be seen from the color code that the total deformation of Ti6Al4V alloy becomes larger as temperature increases, which indicates the densification of Ti6Al4V alloy increased as temperature rises. Ti6Al4V alloy castings are totally densified at $920^{\circ} \mathrm{C}$ and $950{ }^{\circ} \mathrm{C}$, as shown in Fig. 7(d) and 7(e). As temperature increases, young's modulus and yield strength

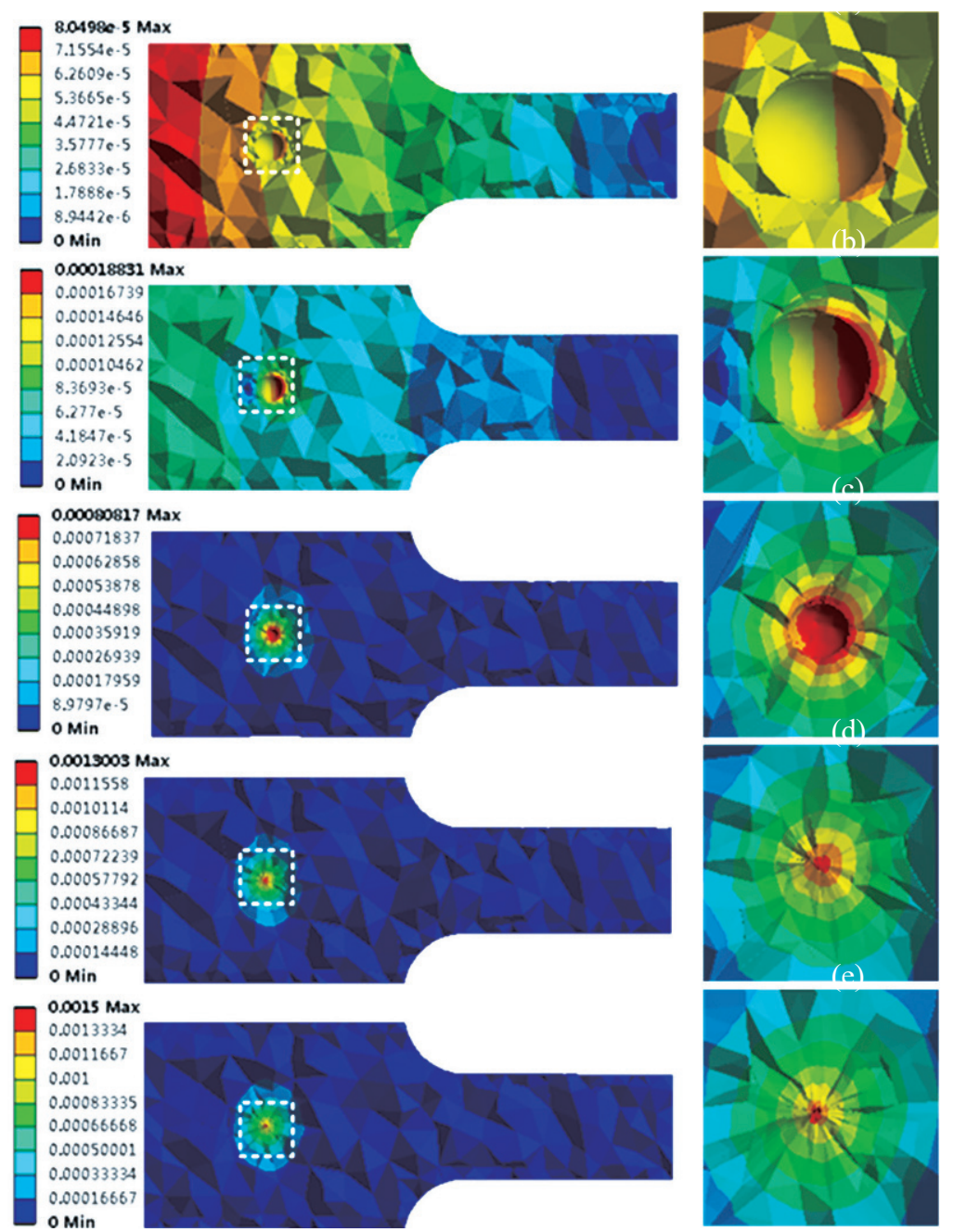

Fig. 7: Total deformation at different HIP temperatures: (a) $750^{\circ} \mathrm{C}$, (b) $850{ }^{\circ} \mathrm{C}$, (c) $900{ }^{\circ} \mathrm{C}$, (d) $920^{\circ} \mathrm{C}$, (e) $950^{\circ} \mathrm{C}$ 


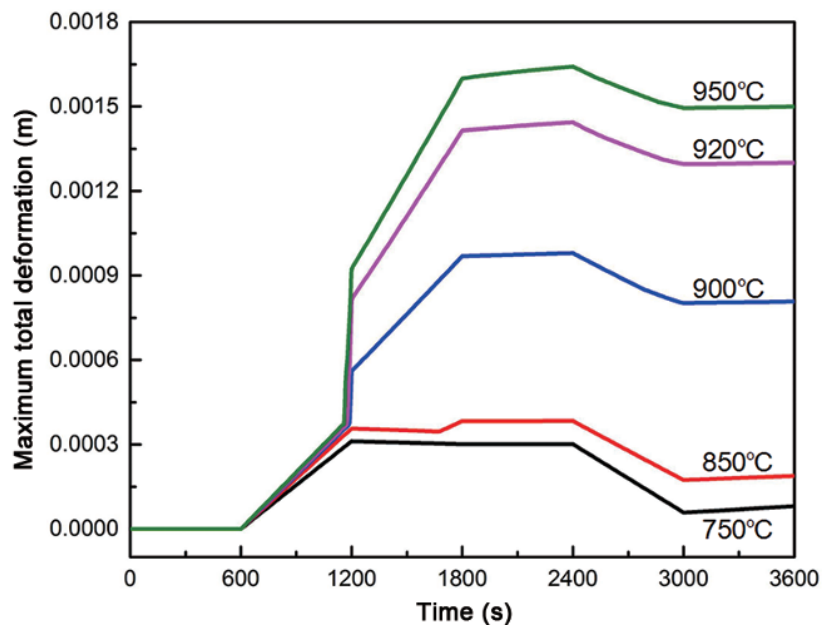

Fig. 8: Changing curve of maximum total deformation at different HIP temperatures

decrease, the nodes move longer until shrinkage is annihilated under the same pressure. Simulation results agree well with the experiment results. Grains will grow up as temperature increases, so the HIP temperature should be as low as possible in the premise of ensuring that the shrinkage is closed. Therefore, $920{ }^{\circ} \mathrm{C}$ is a suitable HIP temperature for Ti6Al4V alloy through simulation.

Figure 8 shows the maximum total deformation of Ti6Al4V alloy during HIP. It can be seen that the maximum total deformation increases as temperature increases, and grows rapidly near $1,200 \mathrm{~s}$. It is speculated that there is a phenomenon of plastic instability around this time point. The yield strength and Young's modulus decrease as temperature increases, so the closure speed of shrinkage becomes faster when a critical point is reached.

\section{Conclusions}

The effect of HIP temperature on densification and microstructure of Ti6Al4V alloy castings were studied by experiment and simulation. Summaries of the above work are as follows:

(1) The microstructure of Ti6Al4V alloy after HIP becomes uniform, however, the thickness of the lamellae becomes thicker as HIP temperature increases.

(2) Both the experimental and the simulation results show that the densification of the Ti6Al4V alloy increases as the HIP temperature increases. The shrinkage is completely closed when
HIP temperature is above $920^{\circ} \mathrm{C}$

(3) The shrinkage completely disappears when HIP temperature is at or higher than $920^{\circ} \mathrm{C}$. However, grains keep on growing as HIP temperature increases. Considering the effect of HIP temperature on the densification and microstructure, $920{ }^{\circ} \mathrm{C}$ is an appropriate HIP temperature for Ti6Al4V alloy in this case.

\section{References}

[1] Fryé T, Strauss J T, Fischer-Bühner J, et al. The Effects of Hot Isostatic Pressing of Platinum Alloy Castings on Mechanical Properties and Microstructures. Johnson Matthey Technol. Rev., 2015, 59: 207-217.

[2] Wang G, Lang L H, Yu W J, et al. Influences of hot-isostaticpressing temperature on the microstructure, tensile properties and tensile fracture mode of 2A12 powder compact. Acta Metall. Sin. (English Lett. ) 2016, 29: 963-974.

[3] Xu L, Guo R, Bai C, et al. Effect of Hot Isostatic Pressing Conditions and Cooling Rate on Microstructure and Properties of Ti-6Al-4V Alloy from Atomized Powder. J. Mater. Sci. Technol. 2017, 30: 1289-1295.

[4] Tam C H, Lee S C, Chang S H, et al. Effects of the temperature of hot isostatic pressing treatment on $\mathrm{Cr}-\mathrm{Si}$ targets. Ceram. Int. 2009, 35: 565-570.

[5] Zhou Y, Zhang Z, Zhao Z, et al. Effects of HIP temperature on the microstructural evolution and property restoration of a $\mathrm{Ni}$ based superalloy. J. Mater. Eng. Perform, 2013, 22: 215-222.

[6] Zhang D Q, Zhou J X, Tang J L, et al. Fast Prediction Model for Closure Pressure in Hot Isostatic Pressing. In: Proc. 4th Int. Conf. Adv. Mater. Manuf. (ICAMMP 2013), Kunming, China, 2013: $1240-1245$.

[7] Jiang H T, Yan X Q, Liu J X, et al. Microstructure and mechanical properties of HIP-ZTC4 during thermal exposure and tensile deformation. Rare Met., 2015, 34: 692-697.

[8] Plessis A. du, Rossouw P. Investigation of Porosity Changes in Cast Ti6Al4V Rods After Hot Isostatic Pressing. J. Mater. Eng. Perform., 2015, 24: 3137-3141.

[9] Nguyen C Van, Deng Y, Bezold A, et al. A combined model to simulate the powder densification and shape changes during hot isostatic pressing. Comput. Methods Appl. Mech. Eng., 2017, 315: 302-315.

[10] Zhou S, Song B, Xue P, et al. Numerical simulation and experimental investigation on densification, shape deformation, and stress distribution of Ti6Al4V compacts during hot isostatic pressing. Int. J. Adv. Manuf. Technol., 2017, 88: 19-31.

[11] Kassner M E, Hayes T A. Creep cavitation in metals. Int. J. Plast., 2003, 19: 1715-1748.

[12] Ha S, Lin D, Shin Y, et al. Experimental and Simulation Analysis of Hot Isostatic Pressing of Gas Atomized Stainless Steel 316L Powder Compacts. Korean J. Met. Mater., 2016, 54: 732-742.

This work was financially supported by the National Natural Science Foundation of China (No. 51475181) and AECC Beijing Institute of Aeronautical Materials. 